\title{
All talk and no action? An analysis of environmental concern, income and greenhouse gas emissions in Switzerland
}

\author{
Journal Article \\ Author(s): \\ Bruderer Enzler, Heidi; Diekmann, Andreas \\ Publication date: \\ 2019-05 \\ Permanent link: \\ https://doi.org/10.3929/ethz-b-000317664
}

Rights / license:

Creative Commons Attribution-NonCommercial-NoDerivatives 4.0 International

Originally published in:

Energy Research \& Social Science 51, https://doi.org/10.1016/j.erss.2019.01.001

Funding acknowledgement:

153715 - Reducing Energy Consumption and Promoting Green Electricity. The Role of Soft Incentives (SNF) 
Bruderer Enzler, H. \& Diekmann, A. (2019). All Talk and No Action? An Analysis of Environmental Concern, Income and Greenhouse Gas Emissions in Switzerland. Energy Research \& Social Science, 51, 12-19. doi:https://doi.org/10.1016/j.erss.2019.01.001.

\title{
All Talk and No Action? An Analysis of Environmental Concern, Income and Greenhouse Gas Emissions in Switzerland
}

\author{
Heidi Bruderer Enzler ${ }^{a^{*}}$ and Andreas Diekmann ${ }^{a, b}$ \\ ${ }^{a}$ ETH Zurich, Environmental Research Group, WEP, 8092 Zurich, Switzerland. \\ ${ }^{b}$ Institute for Advanced Study Berlin, Wallotstraße 19, 14193 Berlin, Germany. \\ *corresponding author: bruderer@soz.gess.ethz.ch
}

\begin{abstract}
Private households play a significant part in reducing greenhouse gas emissions. Therefore, it is important to know which factors are related to emissions. However, most studies so far have focused on income, household size and other structural factors while neglecting the potential relevance of attitudinal variables such as environmental concern. Those studies that did examine environmental attitudes were mostly based on "intent-oriented" measures of pro-environmental behavior instead of actual environmental impacts. The present study brings these lines of research together by analyzing the relationship between emissions, income and environmental attitudes within a framework of multivariate analysis. Furthermore, three specific emissions domains - mobility, housing and food - are analyzed separately and the results are compared to those based on a scale of pro-environmental behavior. All analyses are based on data from a large representative general population survey, the Swiss Environmental Survey 2007 ( $n=3,369$ ), and a subsequent life cycle analysis. The results clearly indicate that next to income, environmental concern is an important predictor of emissions, even when controlling for the effects of income.
\end{abstract}

Keywords: greenhouse gas emissions; pro-environmental behavior; income; environmental concern 


\section{Introduction}

Climate change and its mitigation has been a central topic in political debate and subsequently many countries have set emissions targets. For example, Switzerland currently aims to reduce its domestic greenhouse gas emissions (GHG) by 50\% in comparison to their level in 1990 by 2030 [1] and, at the time of writing, the parliament is discussing further reductions. Private households contribute a large share of the current GHG emissions (for the US, Bin and Dowlatabadi [2] report a share of $80 \%$ of GHG emissions was due to consumer demand; Hertwich and Peters [3] attribute $72 \%$ to household consumption globally). Thus it is important to know which structural, socio-economic or attitudinal factors are related to environmental burdens and whether the correlations are the same for all areas of consumption, including mobility, housing, or food.

\subsection{Intent- Versus Impact-Oriented Behavior}

Previous research on this topic differs regarding how a person's environmental impact or behavior is assessed and what factors are taken into account when analyzing it. These differences are of great theoretical and practical importance since they may lead to different results and hence different suggestions for environmental politics and other practical interventions.

In the social sciences, environmental impacts are generally not studied directly. Instead, the focus is on "pro-environmental behavior" (PEB) which is usually assessed in terms of selfreported frequencies of various environmentally relevant behaviors [e.g. 4, 5-8]. In most cases, this covers a wide range of behaviors from different domains; typical examples are recycling, switching off lights, purchasing organic groceries or refraining from using a car. In addition, these behaviors entail very different ecological impacts. Subsequently, these behaviors are merged into one general or several thematic indexes or latent variables - e.g. recycling, energy conservation or commuting - without weighting the behaviors according to their environmental impacts. Moreover, the selection procedure of behaviors is often insufficiently if at all theoretically grounded. The problem is that unless a PEB scale is carefully designed to cover the most important contributors to a person's environmental impact and unless the individual behaviors are weighed according to impacts, measures of PEB do not reflect impacts adequately.

Stern [9] has labeled this type of measure as "intent-oriented" since the emphasis generally rests on behavior that people associate with being "ecologically sound" while it may have comparatively little impact on actual resource consumption - examples are recycling, or refusing plastic bags in stores. Impact-oriented measures of environmental behavior, in contrast, attempt to assess actual resource consumption. A few studies in social sciences [to our knowledge these are: 10, 11-14] and a long-standing tradition in environmental sciences [e.g. 15, 16-19] have done so. Typically, these studies focus on assessing absolute per capita or household impacts in 
terms of $\mathrm{GHG}$ emissions (in $\mathrm{kg} \mathrm{CO}_{2}$ equivalents), energy requirements (in Joule or $\mathrm{kWh}$ ) or some other unit of ecological impact. Frequently, "direct" and "indirect" impacts are reported separately. Direct impacts result directly from the consumption of energy carriers such as electricity, gas, heating oil, petrol, etc. [20]. Thus, this primarily captures energy use in the home (mainly space heating and electricity use) as well as by transport (i.e. by motorized travel). Indirect impacts are also called "embodied" or "embedded" impacts; they are "embedded" in goods and services in that they originate from the production, transportation and disposal of goods [cf. 21, 22]. This includes a broad range of categories such as food, consumables or services. For the year 2005, Jungbluth, Nathani, Stucki and Leuenberger [23] estimate that $74 \%$ of all GHG emissions due to Swiss consumption were indirect. A few studies further distinguish different categories of consumption, such as transport, food or consumables [e.g. 11, 13, 19, 20, $24,25-27]$. If these emission domains are differentially related to other variables such as income or environmental concern, these distinctions are relevant for practical interventions.

\subsection{Bringing Two Strands of Research Together}

So far, research on intent-oriented environmental behavior and research on actual environmental impacts have progressed rather independently from one another and typically used different analytical methods and explanatory variables. Generally, studies on environmental impacts do not consider attitudinal variables such as environmental concern or values. Instead, they focus mostly on bivariate relationships between environmental burden and structural variables (such as urbanity) and/or socio-demographic variables (such as income or number of people living in the household). Accordingly, these studies typically conclude that socio-demographic factors are important (such as income or household size; e.g. [17, 28]).

In contrast, studies that do account for psychological variables and do so by means of multivariate statistical methods, in turn, are typically carried out by social scientists and (therefore) do not analyze actual environmental impacts but rely on intent-oriented measures. The results of these studies point to the influence of environmental attitudes and values for at least some areas of behavior [for meta-analyses see: 29,30 ] and thus suggest there is a "moral basis" for PEB [31].

Thus, whether socioeconomic conditions or attitudes matter may depend very much on the choice of outcome variable: The former set of results emphasizes the importance of the households' (financial) room for maneuver and thus advocates an incentive based approach, while the latter set of results suggests that raising awareness of the issue at hand may help solve the problem (see online appendix A for a more detailed review of the literature). Very few studies have combined and compared the results obtained based on the two types of outcome measures [to our knowledge these are: 12, 13, 14, 32]. 


\subsection{The Present Study}

The aim of the present study is to bring these lines of research together within a framework of multivariate analysis by analyzing the relationship between GHG emissions and PEB on one hand and income and environmental attitudes on the other hand. We focus on income and environmental concern as explanatory variables as the former has been central to previous research on environmental impacts (e.g. $[18,28,33])$, whereas the latter has been the focal point of studies on PEB. According to a review in 2007 [34], more than half of all publications in environmental psychology have discussed environmental concern. ${ }^{1}$ We understand environmental concern as "the degree to which people are aware of problems regarding the environment and support efforts to solve them and/or indicate a willingness to contribute personally to their solution" [35, p. 485].

We expect that income and emissions are highly and positively correlated (Hypothesis 1 ). This expectation is based on the fact that consumption is costly and at the same time, most consumption contributes to increases in emissions through production, processing and end-oflife treatment or disposal of goods and services (cf. literature review in online appendix A).

Given a "moral basis" for environmental behavior, we would also expect that persons with higher environmental concern cause lower emissions. However, previous research has suggested that people often prefer to ease their environmental conscience by means of low-cost activities - i.e. behavior that entails little inconvenience or costs [36, 37], such as recycling of glass and paper. However, such behavior is often rather symbolic in the sense that it has a comparatively low impact on the environment [13]. Furthermore, people may fall into a trap of self-deception and overestimate their contribution to conservation [38]. Moreover, rebound and moral licensing effects often lower the gains of environmentally responsible behavior [e.g. 39, 40]. For these reasons, we hypothesize that there is a weak negative correlation between environmental concern and actual environmental impact at most (Hypothesis 2).

Since PEB scales mostly consist of items measuring symbolic forms of environmentally responsible behavior [13], every person - irrespective of their wealth and overall consumption may score high on PEB scales. Therefore, we expect that income is not correlated to PEB (Hypothesis 3). By the same reasoning, we expect a strong positive correlation between environmental concern and PEB (Hypothesis 4). Thus, we expect a very different pattern in the effects of income and environmental concern on emissions versus PEB (see Table 1).

\footnotetext{
1 We use the terms environmental concern and environmental attitudes interchangeably. 
Table 1. Overview on expected correlations (hypotheses)

\begin{tabular}{lcc}
\hline Independent variable & Dependent variable \\
\cline { 2 - 3 } & $\begin{array}{c}\text { Strong positive correlation } \\
\text { (Hypothesis 1) }\end{array}$ & Pro-environmental behavior (PEB) \\
Income & $\begin{array}{c}\text { Neak negative correlation at most } \\
\text { (Hypothesis 2) }\end{array}$ & $\begin{array}{c}\text { Strong positive correlation } \\
\text { (Hypothesis 4) }\end{array}$ \\
\hline
\end{tabular}

As there are not many studies distinguishing between different domains of environmental impacts by private consumption, this is a second focus of this study: In addition to analyzing total emissions, three specific domains - mobility, housing and food - are analyzed separately. This allows for the comparing of whether these emissions domains are differentially related to socio-economic and attitudinal variables.

Further, as an additional analysis, we address the question of inequality of overall and domain-specific per capita emissions since such information on distributional aspects is indispensable for the debate on environmental justice. However, environmental justice literature is mainly concerned with the distribution of environmental burdens while there is much less research on the distribution of emissions [for a review see e.g. 41, 42].

\section{Materials and Methods}

\subsection{Participants and Procedure}

All analyses are based on data from the Swiss Environmental Survey 2007, a representative general population study $(n=3369)$. The data collection was based on a two-stage random sample taken from the adult population of Switzerland with a registered telephone extension. In a first step, households were selected randomly from regional strata and notified by mail. The study was described as an investigation into living conditions in Switzerland and not as an environmental study in order to avoid including a disproportionate number of people with an above-average interest in the environment taking part. The households were then contacted by telephone. In the second step of the sampling procedure, one respondent within each household was selected at random from all its members aged 18 or older and being able to respond in German, French or Italian. Foreigners belonging to the resident population were included provided they could complete the survey in one of the three languages mentioned. The telephone interviews were conducted between November 2006 and March 2007. On average they lasted 37 minutes. The resulting response rate was 52\% (RR2, Research, AAPOR). A written follow-up questionnaire was completed by a total of $83 \%$ of those already interviewed $(n=$ 2789). Up to two reminders were issued. 
The resulting sample consists of 56\% females and the average age was 49.9 years (ranging from 18 to 94 years). The median level of education is 12 years. Further information on the sample as well as on procedures and materials can be found in the project documentation [43]. ${ }^{2}$

\subsection{Multiple Imputation of Missing Data}

Missing data was handled by multiple imputation using chained equations (MICE). Multiple imputation is currently considered a state-of-the-art technique to handle missing data [44]. It assumes missingness is at random while - unlike the common practice of listwise deletion - not requiring the data to be missing completely at random [45]. The MICE procedure is regressionbased and creates multiple complete copies of the dataset. Each of these copies contains different estimates for the missing values. In this study, 120 imputed datasets were created using 75 variables. Further information can be found in online appendix $B$.

All analyses that follow are based on the 120 imputed datasets. The results were pooled following Rubin's rules [cf. 46]. To allow for comparison, all multivariate analyses were also carried out with complete cases only (i.e. listwise deletion, see online appendix B). The results are comparable to the results using the imputed data. However, the analyses on imputed data are more efficient, as is indicated by lower standard errors [cf. 44].

\subsection{Estimation of GHG Emissions}

While compiling the questionnaire items regarding behavior for the "Swiss Environmental Survey 2007", Diekmann and Meyer closely collaborated with life cycle experts at the Swiss Federal Laboratories for Materials Science and Technology (Empa) in order to allow for a later life cycle analysis (LCA). Based on the survey responses, Empa subsequently carried out an LCA for every individual respondent, as is reported in Notter, Meyer and Althaus [47]. The results are expressed in annual $\mathrm{kg} \mathrm{CO}_{2}$ equivalents per person.

For the present paper, this LCA was slightly adapted as, depending on the data available, the original computations were based on different variables for different respondents (e.g. home owners vs. persons renting their dwelling). As we strongly suspect the different paths result in different biases, one path was chosen for all respondents and instead of replacing missing values by mean or modal values, we opted for multiple imputations as described above. Furthermore, after consultation with the LCA experts at Empa, a few corrections to individual cases and the procedure in general were applied.

\footnotetext{
2 To test for an environment-related self-selection bias, for the written survey, the index's measures of environmental concern during the oral interview were compared between the participants and non-participants. No significant differences were observed, $t(3132)=.268, p=.789$.
} 
In the present study, we do not distinguish between direct and indirect emissions. Instead, emissions are split into different areas of consumption. Thus, each category includes both direct and indirect emissions. These are: housing (covering space heating, building infrastructure, electricity), mobility (covering travel by air, public transport, car and motorbike), food and non-durable consumer goods. Previous studies have identified food, shelter and mobility as the most important consumption categories (see [3] in general and [23] for Switzerland). Further details regarding the computation of emissions can be found in online appendix B.

\subsection{Intent-Oriented Pro-Environmental Behavior}

Eleven items were used to assess PEB from an intent-oriented perspective: recycling of (1) organic waste, (2) PET, (3) aluminum and (4) tin, (5) frequent or very frequent consumption of organic produce, (6) use of recycled toilet paper and (7) of recycled paper in general, (8) avoidance of standby on the television set, (9) use of energy-saving light bulbs, (10) switching off lights upon leaving a room, and (11) environmentally friendly reaction when feeling cold at home in winter (not turning up heating). All of these items were recoded into binary variables and summed up. This results in a scale ranging from 0 to 11 with high values indicating environmentally friendly behavior ( $M=7.42,95 \% \mathrm{Cl}[7.37,7.50])$. The item wordings and details on the recoding of the responses can be found in online appendix $B$.

The reliability of the scale is rather low (mean of Cronbach's alpha across $M=120, \alpha=$ $.496, n=3369$ ). However, due to the heterogeneous content of the items this is not surprising. Note that PEB is an additive index of self-reported, environmentally responsible behavior which is in contrast to other studies that focus on intentions [e.g. 32].

\subsection{Income and Environmental Concern}

Income is assessed as the net household equivalence income, i.e. the household's disposable income was divided by the square root of the number of individuals living in the household. If possible, income is based on an open question; otherwise it is based on categories. The median equivalence income amounts to CHF 4571 per month ${ }^{3}(95 \% \mathrm{Cl}[4468,4674] ; \mathrm{M}=5256,95 \% \mathrm{Cl}$ [5110, 5401]; $n=3369$ ). Due to its right-skewed distribution, income is logarithmized for all regression analyses to follow.

Environmental concern was measured by the nine five-point items suggested by Diekmann and Preisendörfer [48; for an English translation see online appendix B]. While the items cover three theoretical dimensions - affective, cognitive and conative - a factor analysis on the complete cases produced a one-dimensional solution (principal components: $\chi^{2}(36)=$

$31,000 \mathrm{CHF}$ amounted to roughly 810 USD at the time the survey was started [44]. 
$4657.95, p=.000 ; \mathrm{KMO}=.851 ; 34.5 \%$ of variance explained, $n=3134)$ as put forth by Diekmann and Preisendörfer [48]. The corresponding reliability was $\alpha=.760$ (mean of Cronbach's alpha across $M=120, n=3369$ ). The items were reverse-scored if applicable and an average score was computed. While the resulting scale theoretically ranges from 1 to 5 , its mean is $3.68(95 \% \mathrm{Cl}$ $[3.66,3.70] ; n=3369)$. High values indicate high environmental concern.

In our analyses below, we treat income and environmental concern as two independent pathways to behavior as previous research has reported mixed results on within-country correlations between the two variables $[14,18,49-51] .{ }^{4}$ In addition, we control for further socioeconomic variables such as age, gender and education of respondents as well as household size, type of community and further characteristics of households. We assume that these variables are correlated with pro-environmental behavior and emissions. Further information on the covariates can be found in online appendix B.

\section{Results and Discussion}

The results and discussion section first provides descriptive statistics for the estimated GHG emissions and their unequal distribution across society (section 3.1). Afterwards, the results regarding environmental concern and income are presented with a focus on our hypotheses (section 3.2). A brief discussion of the effects of selected covariates can be found in online appendix B.

\subsection{GHG Emissions and their Unequal Distribution}

\subsubsection{Results}

Estimated average annual GHG emissions per capita amount to $6028 \mathrm{~kg} \mathrm{CO} 2$ equivalents $(95 \% \mathrm{Cl}$ [5904, 6151]). This total is composed of emission in several categories as described in the method section. Figure 1 illustrates the relative shares of the different consumption categories. As expected, mobility and housing represent large shares with $46 \%(2754 \mathrm{~kg}, 95 \% \mathrm{Cl}[2650$, 2859]) and 33\% (1972 kg, 95\% Cl [1907, 2037]), respectively.

\footnotetext{
4 A brief exploratory analyses on potential indirect effects of income on behavior (mediated by environmental concern) suggests these effects are negligible: Based on one randomly selected imputation and using the same covariates as in Table 4, bootstrapped confidence intervals for the indirect effect were computed. For example for total emissions, the results suggest that an increase of $10 \%$ in income is related to an increase of $.07 \%$ in total emission due to the effect of income on environmental concern which in turn affects emissions. For PEB, the indirect effect of a $10 \%$ increase in income is associated with a decrease in PEB of .007 units.
} 


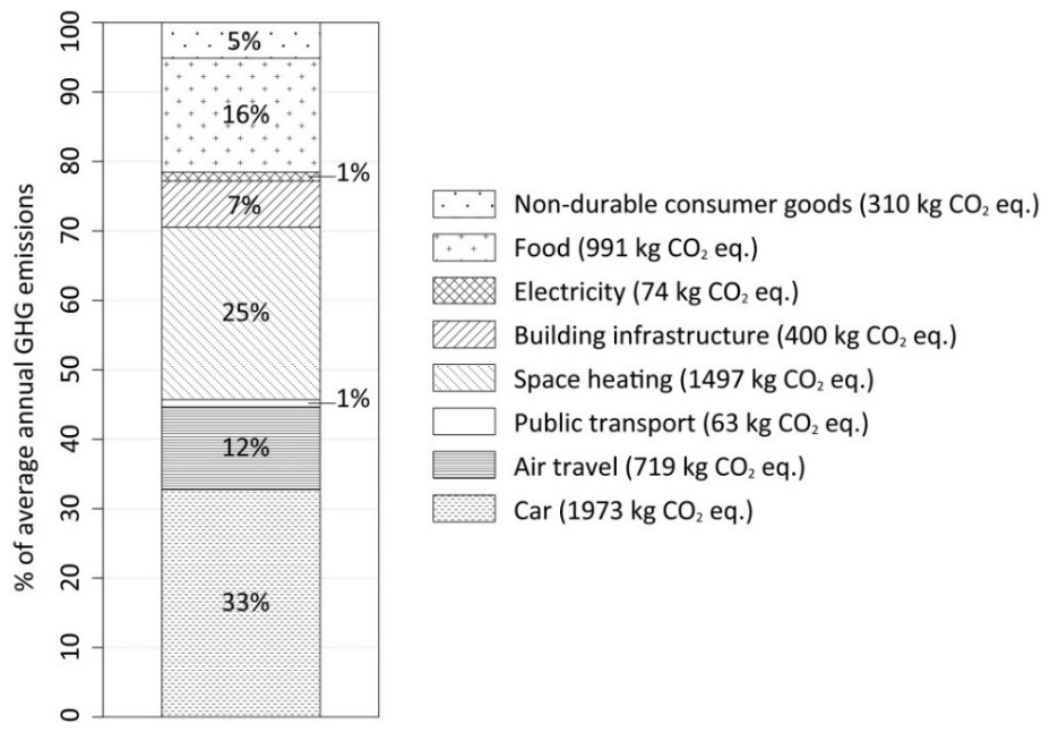

Figure 1. Annual average GHG emissions per capita, divided into subcategories (mean values in brackets)

A comparison of the $10 \%$ of the sample with the lowest per capita emissions $(2342 \mathrm{~kg}, 95 \% \mathrm{Cl}$ [2301, 2383] per person) and the $10 \%$ with the highest emissions $(13984 \mathrm{~kg}, 95 \% \mathrm{Cl}[13475$, 14493]) reveals a factor of 6 between the emissions of these two groups. The $10 \%$ highest emitters cause roughly $23 \%$ of the total emissions of our sample, whereas, for the lowest emission decile, it is only $4 \%$. The factor between the top and bottom emission deciles is much larger for mobility (a factor of 23) than for food (factor 1.3), with the sector of housing in between (factor 4.7). Table 2 gives an overview of the differences between the lowest and the highest emission deciles.

Table 2. Descriptive statistics for the lowest and the highest emission deciles

\begin{tabular}{|c|c|c|c|c|}
\hline & \multicolumn{2}{|c|}{ Lowest emission decile } & \multicolumn{2}{|c|}{ Highest emission decile } \\
\hline & Mean & $95 \% \mathrm{Cl}$ & Mean & $95 \% \mathrm{Cl}$ \\
\hline GHG total [kg CO${ }_{2}$ eq.] & 2342 & 2301,2383 & 13984 & 13475,14493 \\
\hline GHG housing [ $\mathrm{kg} \mathrm{CO} \mathrm{CO}_{2}$ eq.] & 802 & 756,847 & 3769 & 3358,4180 \\
\hline GHG mobility $\left[\mathrm{kg} \mathrm{CO}{ }_{2}\right.$ eq. $]$ & 391 & 354,429 & 8846 & 8268,9425 \\
\hline GHG food [kg $\mathrm{CO}_{2}$ eq.] & 838 & 810,866 & 1058 & 1021,1095 \\
\hline PEB (0-11) & 8.0 & $7.7,8.2$ & 6.9 & $6.6,7.1$ \\
\hline Equivalence income (per month, in thsd CHF) & 4.1 & $3.6,4.5$ & 7.7 & $6.9,8.5$ \\
\hline Environmental concern (1-5) & 3.9 & $3.9,4.0$ & 3.4 & $3.4,3.5$ \\
\hline Number of persons in household & 2.7 & $2.5,2.8$ & 2.0 & $1.9,2.2$ \\
\hline Children in household $(0 / 1)$ & .23 & $.18, .28$ & .13 & $.09, .16$ \\
\hline Female (0/1) & .77 & $.72, .82$ & .37 & $.32, .43$ \\
\hline Age (divided by 10 ) & 5.1 & $4.9,5.3$ & 4.8 & $4.6,4.9$ \\
\hline Years of education & 12.2 & $11.8,12.5$ & 14.0 & $13.7,14.4$ \\
\hline Economically active $(0 / 1)$ & .50 & $.44, .56$ & .77 & $.73, .82$ \\
\hline Car in household $(0 / 1)$ & .53 & $.47, .59$ & .94 & $.92, .97$ \\
\hline City $(0 / 1)$ & .31 & $.26, .37$ & .19 & $.15, .24$ \\
\hline Small or medium-sized town $(0 / 1)$ & .11 & $.07, .14$ & .15 & $.11, .19$ \\
\hline Agglomeration (0/1) & .38 & $.32, .44$ & .44 & $.38, .49$ \\
\hline Rural community $(0 / 1)$ & .21 & $.16, .25$ & .22 & $.17, .27$ \\
\hline Frequency of consumption of organic products (1-5) & 3.5 & $3.3,3.6$ & 3.1 & $3.0,3.2$ \\
\hline Number of days a week with meat consumption & 2.4 & $2.2,2.6$ & 3.6 & $3.4,3.8$ \\
\hline Square footage of apartment or house per person $\left(\mathrm{m}^{2}\right)$ & 41.9 & $39.4,44.4$ & 88.7 & $81.9,95.6$ \\
\hline Air travel for private purposes $(0 / 1)$ & .14 & $.10, .18$ & .71 & $.66, .76$ \\
\hline Low-energy building $(0 / 1)$ & .29 & $.22, .38$ & .15 & $.10, .21$ \\
\hline Home owner (0/1) & .38 & $.33, .44$ & .49 & $.44, .55$ \\
\hline
\end{tabular}

Note: $n$ varies between imputations ( $n=312-358$ for lowest emission decile, $n=323-353$ for highest emission decile). 


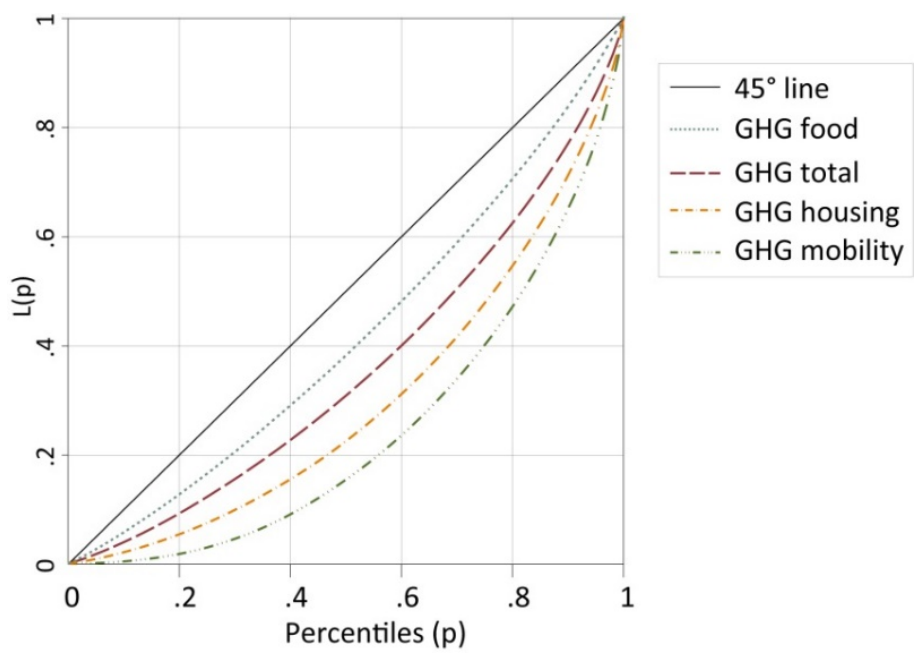

Figure 2. Lorenz curves for total GHG emissions per capita and for those by housing, mobility and food (based on one imputation only)

This unequal distribution is particularly true for mobility and housing, and less so for food (see Lorenz curves in Figure 2). Figure 3 visualizes average annual per capita emissions by income deciles, split up into the different categories. A comparison of the emissions of the highest and lowest income deciles reveals a factor of about 1.8 between the emissions by these two groups (roughly $8762 \mathrm{~kg}$ per person $(95 \% \mathrm{Cl}[8184,9340])$ and $4792 \mathrm{~kg}$ per person (95\% Cl [4420, 5164]), respectively). The top income percentile causes approximately $15 \%$ of the total emissions of our sample, whereas, for the lowest decile, it is about $8 \%$.

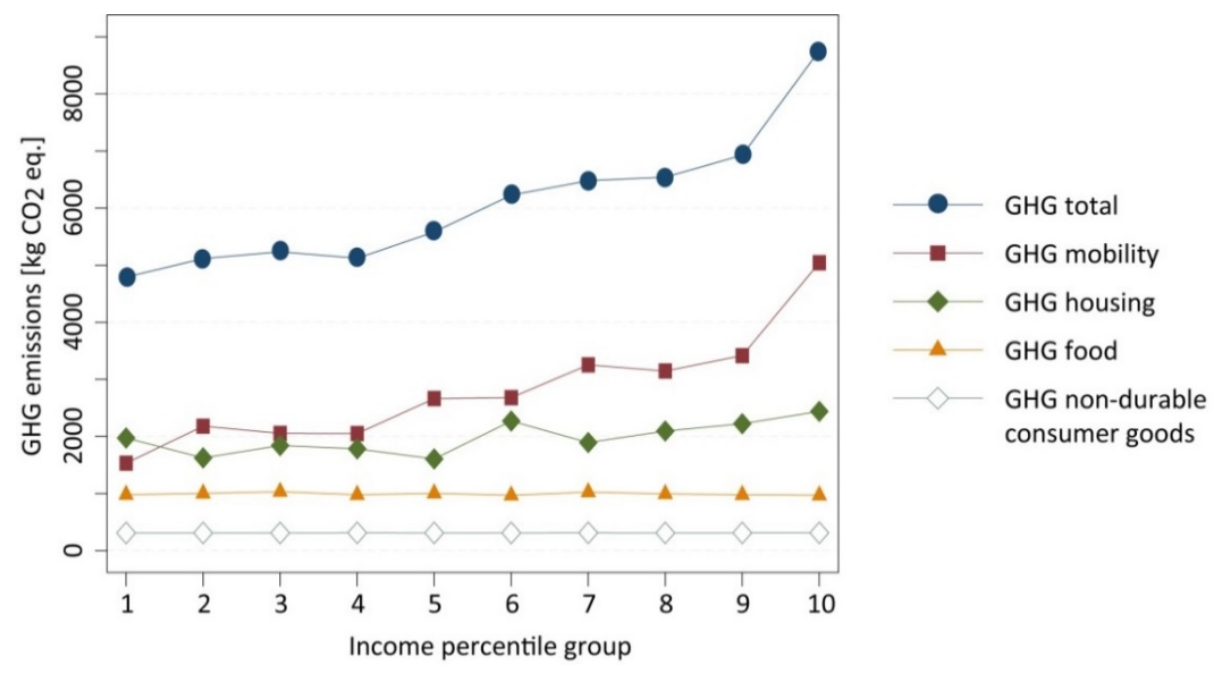

Figure 3. Mean annual GHG emissions by deciles of equivalence income, split for areas of consumption

\subsubsection{Discussion}

In comparison to other studies in Switzerland, our mean values seem rather low as Jungbluth, Nathani, Stucki and Leuenberger [23] conclude that most studies on Switzerland report $\mathrm{CO}_{2}$ equivalents per capita at in between 8.6 and 13 tons. The low estimate of the present study can 
be explained by the fact that the survey we used did not assess all categories of consumption. In particular, most services (including health services, or education) and many long-lived goods (such as furniture, electronic equipment, household equipment, or clothing) are not covered.

In line with previous research, we observe very unequal distributions of emissions. Since previous studies mostly have reported comparisons of income groups at the household level (not per capita), comparisons are not straightforward. On the household level, Druckman \& Jackson's results [33] suggest a factor of 2.2 between the emissions of the highest and lowest income deciles in the UK. Büchs, Bardsley and Schnepf [52] (also for the UK) report a factor of 2.7 and Kennedy, Krahn and Krogman [53] (for Canada) a factor of 2.2 between the top and bottom income quintiles (not controlling for household size). The former study also indicates that the distribution is most unequal for transportation (factor 4.6) and less so for home energy use (factor 1.6). This finding also mirrors our results (cf. Figure 3).

\subsection{Correlations to Income and Environmental Concern}

To analyze the effects of income and environmental concern on GHG emissions and on PEB, bivariate correlations and multivariate ordinary least squares (OLS) regression models were estimated. For these analyses, GHG emissions were logarithmized due to their skewed distributions. We generally considered only those predictors that had not been used to estimate emissions (except for gender and age in the case of food). Otherwise, correlations would be overestimated by design - as presumably is the case in many studies that rely on expenditures both to estimate and predict emissions in the subsequent analyses (this is for example pointed out by [24]). This in turn entails that our regression analyses do not include certain variables, such as living area or type of building, which would - by definition - be correlated to environmental impact.

\subsubsection{Results}

The correlation analysis reveals that higher total emissions as well as emissions from mobility are related to both higher income and lower environmental concern (see Table 3). In contrast, emissions by housing are only related to income but not to environmental concern and for emissions by food, the opposite is true. Furthermore, lower environmental concern and higher income are both related to lower values on the intent-oriented scale (PEB), i.e. less environmentally friendly behavior. 
Table 3. Bivariate correlations (estimated using Stata's "mibeta" with the option "fisherz", $n=3369$ )

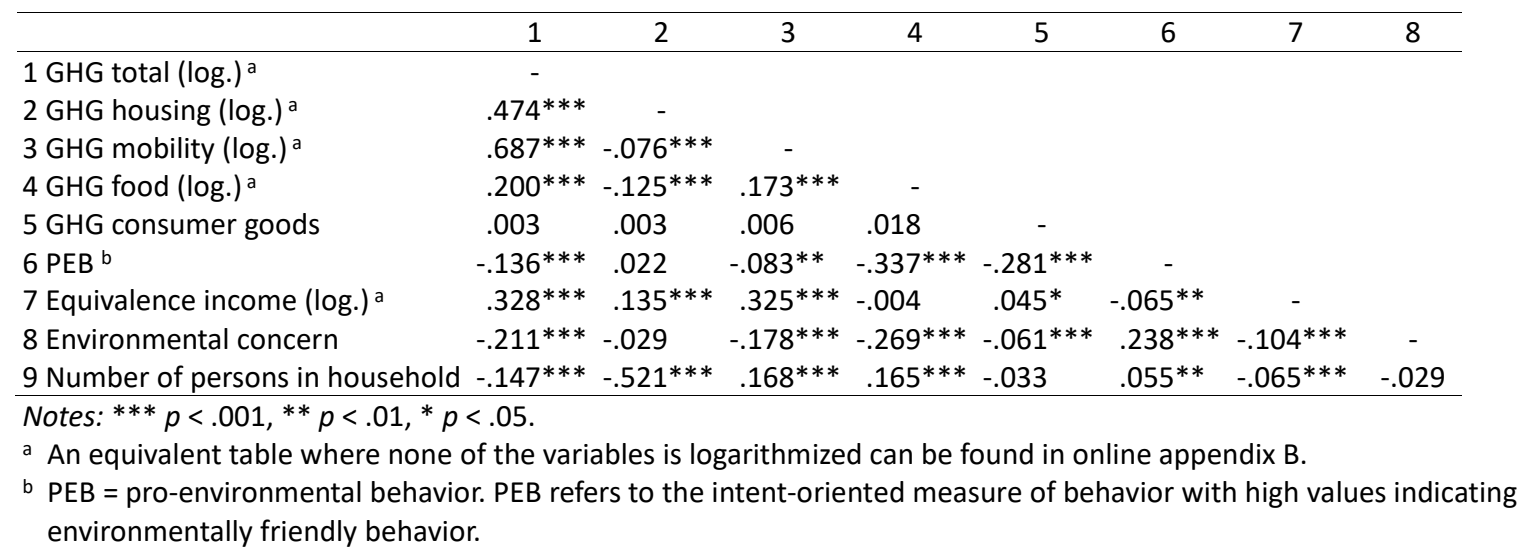

Table 4. OLS regression models for intent-oriented PEB and GHG emissions per capita (total and categories)

\begin{tabular}{|c|c|c|c|c|c|}
\hline & PEB $^{a}$ & $\begin{array}{l}\text { GHG } \\
\text { Total } \\
\text { (log.) }\end{array}$ & $\begin{array}{c}\text { GHG } \\
\text { Housing } \\
{\text { (log. })^{b}}^{\text {b }}\end{array}$ & $\begin{array}{c}\text { GHG } \\
\text { Mobility } \\
(\log .)^{b}\end{array}$ & $\begin{array}{l}\text { GHG } \\
\text { Food } \\
(\log .)^{b}\end{array}$ \\
\hline Equivalence income (log.) & $\begin{array}{c}-0.25 * * * \\
(-3.58)\end{array}$ & $\begin{array}{c}0.18^{* * *} \\
(10.20)\end{array}$ & $\begin{array}{c}0.14^{* * *} \\
(5.10)\end{array}$ & $\begin{array}{c}0.34^{* * *} \\
(8.14)\end{array}$ & $\begin{array}{c}-0.02 \\
(-1.57)\end{array}$ \\
\hline Environmental concern (1-5) & $\begin{array}{c}0.67 * * * \\
(13.60)\end{array}$ & $\begin{array}{c}-0.09 * * * \\
(-7.85)\end{array}$ & $\begin{array}{l}-0.05^{*} \\
(-2.55)\end{array}$ & $\begin{array}{c}-0.11 * * * \\
(-3.97)\end{array}$ & $\begin{array}{r}-0.10 * * * \\
(-13.45)\end{array}$ \\
\hline Number of persons in household & $\begin{array}{c}0.20 * * * \\
(6.40)\end{array}$ & $\begin{array}{r}-0.11 * * * \\
(-13.78)\end{array}$ & $\begin{array}{c}-0.26 * * * \\
(-21.95)\end{array}$ & $\begin{array}{c}-0.08 * * * \\
(-4.24)\end{array}$ & $\begin{array}{c}0.02 * * * \\
(3.53)\end{array}$ \\
\hline Children in household $(0 / 1)$ & $\begin{array}{l}-0.21^{*} \\
(-2.01)\end{array}$ & $\begin{array}{c}0.04 \\
(1.50)\end{array}$ & $\begin{array}{c}0.04 \\
(0.88)\end{array}$ & $\begin{array}{c}0.01 \\
(0.15)\end{array}$ & $\begin{array}{l}-0.02 \\
(-1.33)\end{array}$ \\
\hline Female & $\begin{array}{c}0.24 * * * \\
(3.65)\end{array}$ & $\begin{array}{c}-0.15 * * * \\
(-9.39)\end{array}$ & $\begin{array}{c}0.05 \\
(1.90)\end{array}$ & $\begin{array}{c}-0.36 * * * \\
(-9.68)\end{array}$ & $\begin{array}{r}-0.17 * * * \\
(-18.12)\end{array}$ \\
\hline Age (divided by 10 ) & $\begin{array}{c}0.22 * * * \\
(8.99)\end{array}$ & $\begin{array}{c}-0.02 * * \\
(-2.64)\end{array}$ & $\begin{array}{c}0.07 * * * \\
(6.78)\end{array}$ & $\begin{array}{c}-0.15^{* * *} \\
(-10.47)\end{array}$ & $\begin{array}{r}-0.02 * * * \\
(-7.09)\end{array}$ \\
\hline Years of education & $\begin{array}{c}0.10^{* * *} \\
(7.57)\end{array}$ & $\begin{array}{c}0.01 * * * \\
(4.82)\end{array}$ & $\begin{array}{l}0.02^{* *} \\
(3.45)\end{array}$ & $\begin{array}{c}0.05^{* * *} \\
(6.61)\end{array}$ & $\begin{array}{r}-0.01 * * * \\
(-7.79)\end{array}$ \\
\hline Economically active $(0 / 1)$ & $\begin{array}{c}0.15 \\
(1.86)\end{array}$ & $\begin{array}{c}0.03 \\
(1.47)\end{array}$ & $\begin{array}{l}-0.05 \\
(-1.38)\end{array}$ & $\begin{array}{c}0.19 * * * \\
(3.98)\end{array}$ & $\begin{array}{c}0.01 \\
(0.86)\end{array}$ \\
\hline Car in household $(0 / 1)$ & & $\begin{array}{c}0.31 * * * \\
(13.17)\end{array}$ & & $\begin{array}{c}1.65 * * * \\
(26.90)\end{array}$ & \\
\hline $\begin{array}{l}\text { German-speaking area } \\
\text { French-speaking area }\end{array}$ & $\begin{array}{c}r e f . \\
-0.43^{* * *} \\
(-4.89)\end{array}$ & $\begin{array}{l}\text { ref. } \\
0.04 \\
(1.79)\end{array}$ & $\begin{array}{c}\text { ref. } \\
-0.18^{* * *} \\
(-4.90)\end{array}$ & $\begin{array}{c}\text { ref. } \\
0.20 * * * \\
(3.87)\end{array}$ & $\begin{array}{c}\text { ref. } \\
0.03^{*} \\
(2.18)\end{array}$ \\
\hline Italian-speaking area & $\begin{array}{c}-0.52^{* * *} \\
(-3.96)\end{array}$ & $\begin{array}{c}0.04 \\
(1.08)\end{array}$ & $\begin{array}{c}-0.10 \\
(-1.71)\end{array}$ & $\begin{array}{l}0.16^{*} \\
(1.96)\end{array}$ & $\begin{array}{r}-0.11 * * * \\
(-5.68)\end{array}$ \\
\hline City & ref. & ref. & ref. & ref. & ref. \\
\hline Small or medium-sized town & $\begin{array}{c}0.45^{* * *} \\
(4.12)\end{array}$ & $\begin{array}{c}0.07 * * \\
(2.78)\end{array}$ & $\begin{array}{c}0.18 * * * \\
(4.39)\end{array}$ & $\begin{array}{l}-0.14^{*} \\
(-2.23)\end{array}$ & $\begin{array}{c}0.06 * * * \\
(3.59)\end{array}$ \\
\hline Agglomeration & $\begin{array}{c}0.36 * * * \\
(4.16)\end{array}$ & $\begin{array}{l}0.05^{*} \\
(2.20)\end{array}$ & $\begin{array}{l}0.07^{*} \\
(2.04)\end{array}$ & $\begin{array}{c}-0.10 \\
(-1.81)\end{array}$ & $\begin{array}{c}0.06 * * * \\
(4.79)\end{array}$ \\
\hline Rural community & $\begin{array}{c}0.49 * * * \\
(4.78)\end{array}$ & $\begin{array}{c}0.08 * * \\
(3.14)\end{array}$ & $\begin{array}{c}0.05 \\
(1.26)\end{array}$ & $\begin{array}{c}-0.06 \\
(-0.96)\end{array}$ & $\begin{array}{c}0.12 * * * \\
(8.13)\end{array}$ \\
\hline Aggregate distance to local facilities ( $\mathrm{km}$, log.) & $\begin{array}{c}0.05 \\
(1.03)\end{array}$ & $\begin{array}{c}0.01 \\
(0.55)\end{array}$ & & $\begin{array}{c}0.01 \\
(0.26)\end{array}$ & \\
\hline Constant & $\begin{array}{c}2.13 * * * \\
(6.61)\end{array}$ & $\begin{array}{l}8.54 * * * \\
(107.28)\end{array}$ & $\begin{array}{c}7.29 * * * \\
(56.16)\end{array}$ & $\begin{array}{c}6.33^{* * *} \\
(34.30) \\
\end{array}$ & $\begin{array}{l}7.54 * * * \\
(164.51)\end{array}$ \\
\hline $\begin{array}{l}\text { Number of observations } \\
\text { Adjusted } R^{2}\end{array}$ & $\begin{array}{l}3369 \\
0.116\end{array}$ & $\begin{array}{l}3369 \\
0.267\end{array}$ & $\begin{array}{l}3369 \\
0.316\end{array}$ & $\begin{array}{l}3369 \\
0.459\end{array}$ & $\begin{array}{l}3369 \\
0.229\end{array}$ \\
\hline
\end{tabular}

Notes: $* * * p<.001, * * p<.01, * p<.05 . t$ values in brackets.

a $\mathrm{PEB}=$ pro-environmental behavior. $\mathrm{PEB}$ refers to the intent-oriented measure of behavior with high values indicating environmentally friendly behavior.

b GHG emissions by housing were estimated at the household level and then divided by the number of persons living in the household. Emissions by mobility and by food, on the other hand, solely relate to the respondents' personal travel and eating habits, respectively. 
The results of the multivariate regression analyses can be found in Table 4. Information on the control variables as well as standardized regression coefficients and models with complete cases only (listwise deletion) can be found in online appendix B.

The overall explanatory power of the models ranges from 0.12 to 0.46 (as the values of adjusted $R^{2}$ in Table 4 indicate). The results indicate a significant correlation between income and GHG emissions as well as PEB. For the latter, a one percent increase in income is associated with a decrease of 0.0025 units (on a scale from 0 to 11), while for overall GHG emissions, a one percent increase in income is related to a $0.18 \%$ increase. Exploring the three dimensions of emissions separately, the increase for emissions by housing is $0.14 \%$, for emissions by mobility it is $0.34 \%$, while there is no significant coefficient for food consumption.

For environmental concern, there is a clear pattern indicating that higher concern is correlated to more environmentally friendly behavior: A one-unit increase in concern is associated with a decrease of $8.61 \%$ in total emissions and decreases of $4.88 \%, 10.42 \%$ and $9.52 \%$ in emissions by housing, mobility and food, respectively. Furthermore, a one-unit increase in environmental concern is linked to an increase of 0.67 units in PEB.

\subsubsection{Discussion}

As expected, we find strong effects of income on emissions (Hypothesis 1) and of environmental concern on PEB (Hypothesis 4). However, contrary to expectations, the effects of income on PEB (Hypothesis 3) and of environmental concern on emissions (Hypothesis 2) are also clearly discernable. Only the correlation between income and emissions by food is neither significant in bivariate nor multivariate analysis. This suggests that poorer and richer households alike generate the same level of emissions by food. Affluence may instead be related to a qualitative shift toward more expensive products, including organic food [54].

The income effect is larger for mobility than for housing - a finding similar to previous research $[24,25]$. Despite a very high degree of overall motorization in Switzerland, richer households spend much more money on fossil fuel consuming transportation than households that are less well off. While the correlation between income and PEB reaches statistical significance, our results suggest that its practical meaning might be rather negligible (e.g. doubling income is merely associated with a decrease in PEB of 0.17 units).

To our surprise, the effects of environmental concern on emissions are significant for all domains of consumption. Regarding the overall impact, this is in line with three previous studies $[12,14,18,32]$ that analyze environmental concern or a related construct, while other researchers did not find any effects $[10,13]$. Regarding emissions from private transport, Nässén, Andersson, Larsson and Holmberg [18] report a negative correlation. In contrast, Poortinga, Steg and Vlek [11] neither find any effect on transport nor on home energy use while 
Diekmann and Jann [13] a negative correlation to energy requirements by food but a positive (sic!) correlation to residential energy use (controlling for income and various other factors).

Given our expectations, the effects of environmental concern on emissions are also surprisingly large (with a one-unit increase in concern being associated with $4.88 \%$ to $10.42 \%$ decreases in emissions for the different domains). While the effects are similar for mobility and food, it is considerably lower for housing (about half in size). We suspect this difference may at least in part be due to the fact that in the domain of housing, many decisions with long-term consequences are made by home owners, while tenants $-62 \%$ of the Swiss households [55] are subjected to their landlord's choices. Furthermore, consumers may not even be aware of the environmental impacts associated with their housing arrangements. On the other hand, there is more room for decision-making in the area of mobility and food consumption, and in line with this, we observe a considerable impact of respondents' environmental concern.

Finally, as the bivariate correlations indicate, PEB only explains a small proportion of the variance in actual impacts - same in previous research: one study has reported a weak but negative correlation between household energy use and PEB [12], another found no correlation at all between carbon footprints and PEB [14]. Thus, conventional measures of PEB and actual impacts should not be considered as equivalent despite the similar patterns of correlations reported further above.

\section{Conclusions}

At the heart of current environmental policies is the reduction of environmental impacts - for example in terms of greenhouse gas emissions. However, so far, most research taking into account psychological determinants of environmentally relevant behavior has focused on socalled intent-oriented measures of pro-environmental behavior (PEB). Such measures do not necessarily describe impacts adequately - in our study, we find a correlation of $r=-.136$ between PEB and emissions. However, to our surprise, when analyzing both "subjective" PEB and "objective" emissions, we find a similar pattern of relationships for the two key independent variables, income and environmental concern. This not only indicates that environmental concern matters - i.e. those indicating more concern do cause less emissions - but it also points to the validity of conventional scales of self-reported PEB. Yet, there are differences in the strength of the relations whereby income has a larger impact on emissions than on PEB while the relation with environmental concern seems to be smaller for emissions in comparison to PEB (see standardized coefficients in online appendix B). Separate analyses of the emission domains housing, mobility and food lead to similar results; differences may in part be attributable to a lack of agency (e.g. in the case of tenants) or awareness of environmental impacts [56]. 
In sum, the low correlation between emissions and PEB as well as the fact that not all emission domains and PEB were equally related to other variables suggest that future research is well advised to use policy-compatible measures of behavior, i.e. measures of impact, instead of conventional PEB scales. Since computing environmental impact is quite complex and requires interdisciplinary work and considerably more resources than simple measures of PEB, an alternative would be to focus on a set of easily measurable indicators of individual behaviors with a close connection between the extent of the behavior and its environmental consequences, e.g. the square footage of one's home or the distance traveled by car.

In our analyses, income and environmental concern only account for part of the variance of overall GHG emissions. The positive message that can be derived from this is that the impact of income on emissions is far from perfect. Even in high-income groups there is a large variation of GHG-related consumption patterns. Environmental concern may thus contribute to spending income in more environmentally friendly ways, for example, by shifting consumption to less carbon intensive alternatives, such as vegetarian meals as opposed to eating meat, or ecological tourism instead of long distance flights. Clearly, carbon tax or cap and trade measures are effective policies to shift consumption pattern. However, for practical interventions not only monetary but also soft incentives may prove useful [57].

In general, research concludes that both structural and cultural changes towards more sustainable lifestyles are needed (e.g. $[18,53])$. Recently, Druckman, Buck, Hayward and Jackson [58] have proposed that resource use should not only be discussed as such but also in combination with time use. How do we spend discretionary time? From a philosophical point of view, we should keep in mind that people cause emissions as a means to achieve a "good life" $[59$, p. 228]. What ought to be understood as a "good life" is a question open to societal/political debate. What are legitimate needs and acceptable ways of meeting them? Finally, given our results on the distribution of emissions, we would like emphasize the importance of taking into account that environmental impacts are not evenly spread across all segments of society. This not only suggests that the potential for emission reductions differs greatly between households, but also that policies should be designed carefully in order to avoid placing a disproportional burden on low-income households (i.e. being regressive, cf. [60]).

However, there are limitations to the present study. Despite multivariate regression analyses one should be cautious inferring causality between the variables of interest. For this purpose, future research may consider experimental or longitudinal designs. Furthermore, the present study was carried out in Switzerland and the question remains to what extent the results would generalize to other high-income, high-emission countries. Switzerland is one of the richest OECD countries and ranks high in environmental concern [51]. Despite this, our hypotheses are not country-specific. We suppose that Switzerland is a good test case for 
exploring the relations between income, environmental concern and outcome-measures of environmental behavior and emissions. Moreover, studies in other industrialized countries, although based on different methods and operationalizations, support our key findings $[14,18$, $25,32]$.

Notwithstanding the obvious allure of life cycle analyses, the related blind spots should always be kept in mind. First, there is imprecision associated with conversion factors from behavior to impacts, for example, from distances to impacts. Second, a LCA cannot cover all relevant behavior. In principle, the LCA carried out for this study could be further improved for example by covering additional fields of consumption (such as electronic equipment or furniture) or by capturing relevant behavior in more detail - for example, by incorporating information on car fuel efficiency or actual heating energy use. However, there is a tradeoff between costs and benefits, feasibility and precision. Much of the desired, more detailed information is not reliably accessible by means of questionnaires.

Third, the analysis is based on responses to survey questions and thus self-reported descriptions of living situations and behavior. This is - same as in the case of PEB - a potential source of bias: On the one hand, respondents may not have the desired information or not be willing to share it. On the other hand, respondents may attempt to portray themselves as environmentally responsible consumers and thus downplay their resource use. However, our LCA is only in part based on behavior commonly associated with being environmentally responsible. For example, respondents may not be aware of the fact that the environmental impact of housing is directly related to the square footage of their apartments. Instead of underestimating the size of their homes, they may even overestimate the actual value as it may seem socially desirable to live in large dwellings. Furthermore, the items used for the LCA were part of a broader survey and respondents were not aware that their responses would be used to compute carbon emissions. Thus, we believe that the LCA results might be less prone to bias by self-reporting than conventional measures of PEB. A study by Attari, DeKay, Davidson and Bruine de Bruin [38] supports this notion in two ways: When asked for the most effective way of reducing energy use, the majority of respondents named - in contrast to experts' recommendations - a type of curtailment behavior such as turning off lights. Moreover, participants overestimated the energy use by low-energy activities (e.g. using a laptop) and underestimated the energy requirements by high-energy behavior (e.g. space heating). However, despite this line of reasoning, future research may want to consider complementing or replacing survey data with observational data or information from other sources such as registers of buildings and dwellings. 


\section{Acknowledgments:}

This paper is part of the project "Reducing Energy Consumption and Promoting Green Electricity. The Role of Soft Incentives" which is part of the National Research Programme "Managing Energy Consumption" (NRP 71) of the Swiss National Science Foundation (project number 407140_153715). The Swiss Environmental Survey 2007 was funded by the Swiss National Science Foundation (project number 100012-107835), the Swiss Federal Office for the Environment, the cantons of Basel City (environment and energy office) and Zurich (waste, water, energy and air office), the central Swiss cantons (environment offices) and the environment and health protection offices of the city of Zurich. The Swiss Federal Statistical Office provided financial and methodological support, influenced neither methods nor results. Our particular thanks go to Dominic Notter and Hans-Jörg Althaus from the Swiss Federal Laboratories for Materials Science and Technology (Empa) and Reto Meyer from ETH.

\section{References}

[1] Swiss Federal Office for the Environment FOEN, Switzerland targets 50\% reduction in greenhouse gas emissions by 2030, 2015. http://www.bafu.admin.ch/klima/03449/12696/index.html?lang=en\&msgid=56394. (Accessed 2015.03.25.

[2] S. Bin, H. Dowlatabadi, Consumer lifestyle approach to US energy use and the related CO2 emissions, Energy Policy 33(2) (2005) 197-208.

[3] E.G. Hertwich, G.P. Peters, Carbon Footprint of Nations: A Global, Trade-Linked Analysis, Environ Sci Technol 43(16) (2009) 6414-6420.

[4] F. Kaiser, General measure of ecological behavior, J Appl Soc Psychol 28(5) (1998) 395-422.

[5] P.W. Schultz, L. Zelezny, N.J. Dalrymple, A multinational perspective on the relation between JudeoChristian religious beliefs and attitudes of environmental concern, Environ Behav 32(4) (2000) 576-591.

[6] F. Kaiser, M. Wilson, Assessing people's general ecological behavior: A cross-cultural measure, J Appl Soc Psychol 30(5) (2000) 952-978.

[7] E. Olli, G. Grendstad, D. Wollebaek, Correlates of environmental behaviors - Bringing back social context, Environ Behav 33(2) (2001) 181-208.

[8] C. Bratt, P.C. Stern, E. Matthies, V. Nenseth, Home, Car Use, and Vacation: The Structure of Environmentally Significant Individual Behavior, Environ Behav (2014).

[9] P.C. Stern, Toward a Coherent Theory of Environmentally Significant Behavior, Journal of Social Issues 56(3) (2000) 407-424.

[10] W. Abrahamse, L. Steg, How do socio-demographic and psychological factors relate to households' direct and indirect energy use and savings?, Journal of Economic Psychology 30(5) (2009) 711-720.

[11] W. Poortinga, L. Steg, C. Vlek, Values, environmental concern, and environmental behavior - A study into household energy use, Environ Behav 36(1) (2004) 70-93.

[12] B. Gatersleben, L. Steg, C. Vlek, Measurement and determinants of environmentally significant consumer behavior, Environ Behav 34(3) (2002) 335-362.

[13] A. Diekmann, B. Jann, Sind die empirischen Ergebnisse zum Umweltverhalten Artefakt? Ein Beitrag zum Problem der Messung von Umweltverhalten [Are the empirical results regarding environmental behavior artefacts? A contribution to the problem of measuring environmental behavior], Umweltpsychologie 4(1) (2000) 64-75.

[14] E.H. Kennedy, H. Krahn, N.T. Krogman, Are we counting what counts? A closer examination of environmental concern, pro-environmental behaviour, and carbon footprint, Local Environment 20(2) (2015) 220-236.

[15] A.C. Kerkhof, S. Nonhebel, H.C. Moll, Relating the environmental impact of consumption to household expenditures: An input-output analysis, Ecol Econ 68(4) (2009) 1160-1170.

[16] C.L. Weber, H.S. Matthews, Quantifying the global and distributional aspects of American household carbon footprint, Ecol Econ 66(2-3) (2008) 379-391.

[17] H.C. Moll, K.J. Noorman, R. Kok, R. Engström, H. Throne-Holst, C. Clark, Pursuing More Sustainable Consumption by Analyzing Household Metabolism in European Countries and Cities, Journal of Industrial Ecology 9(1-2) (2005) 259-275.

[18] J. Nässén, D. Andersson, J. Larsson, J. Holmberg, Explaining the Variation in Greenhouse Gas Emissions Between Households: Socioeconomic, Motivational, and Physical Factors, Journal of Industrial Ecology 19(3) (2015) 480-489. 
[19] A. Poom, R. Ahas, How Does the Environmental Load of Household Consumption Depend on Residential Location?, Sustainability-Basel 8(9) (2016).

[20] D. Wiedenhofer, M. Lenzen, J.K. Steinberger, Energy requirements of consumption: Urban form, climatic and socio-economic factors, rebounds and their policy implications, Energy Policy 63 (2013) 696707.

[21] K. Vringer, K. Blok, The direct and indirect energy requirements of households in the Netherlands, Energy Policy 23(10) (1995) 893-910.

[22] A. Druckman, T. Jackson, The carbon footprint of UK households 1990-2004: A socio-economically disaggregated, quasi-multi-regional input-output model, Ecol Econ 68(7) (2009) 2066-2077.

[23] N. Jungbluth, C. Nathani, M. Stucki, M. Leuenberger, Environmental Impacts of Swiss Consumption and Production. A combination of input-output analysis with life cycle assessment., Environmental studies, Federal Office for the Environment FOEN, Bern, 2011.

[24] S. Ala-Mantila, J. Heinonen, S. Junnila, Relationship between urbanization, direct and indirect greenhouse gas emissions, and expenditures: A multivariate analysis, Ecol Econ 104(0) (2014) 129-139.

[25] M. Büchs, S.V. Schnepf, Who emits most? Associations between socio-economic factors and UK households' home energy, transport, indirect and total CO2 emissions, Ecol Econ 90 (2013) 114-123.

[26] I. Gough, S. Abdallah, V. Johnson, J. Ryan-Collins, C. Smith, The distribution of total greenhouse gas emissions by households in the UK, and some implications for social policy., CASE Paper, Centre for Analysis of Social Exclusion, London School of Economics, London, 2011.

[27] J. Nässén, Determinants of greenhouse gas emissions from Swedish private consumption: Timeseries and cross-sectional analyses, Energy 66 (2014) 98-106.

[28] M. Lenzen, M. Wier, C. Cohen, H. Hayami, S. Pachauri, R. Schaeffer, A comparative multivariate analysis of household energy requirements in Australia, Brazil, Denmark, India and Japan, Energy 31(2-3) (2006) 181-207.

[29] S. Bamberg, G. Möser, Twenty years after Hines, Hungerford, and Tomera: A new meta-analysis of psycho-social determinants of pro-environmental behaviour, J Environ Psychol 27(1) (2007) 14-25.

[30] J.M. Hines, H.R. Hungerford, A.N. Tomera, Analysis and Synthesis of Research on Responsible Behavior: A Meta-Analysis, Journal of Environmental Education 18(2) (1987) 1-8.

[31] L. Whitmarsh, Behavioural responses to climate change: Asymmetry of intentions and impacts, J Environ Psychol 29(1) (2009) 13-23.

[32] S. Moser, S. Kleinhückelkotten, Good Intents, but Low Impacts: Diverging Importance of Motivational and Socioeconomic Determinants Explaining Pro-Environmental Behavior, Energy Use, and Carbon Footprint, Environ Behav 50(6) (2017) 626-656.

[33] A. Druckman, T. Jackson, Household energy consumption in the UK: A highly geographically and socio-economically disaggregated model, Energy Policy 36(8) (2008) 3177-3192.

[34] T.L. Milfont, Psychology of environmental attitudes: a cross-cultural study of their content and structure, The University of Auckland, Auckland, 2007.

[35] R.E. Dunlap, R.E. Jones, Environmental Concern: Conceptual and Measurement Issues, in: R.E. Dunlap, W. Michelson (Eds.), Handbook of Environmental Sociology, Greenwood Press, London, 2002, pp. 482-524.

[36] A. Diekmann, P. Preisendörfer, Environmental Behavior - Discrepancies between Aspirations and Reality, Ration Soc 10(1) (1998) 79-102.

[37] A. Diekmann, P. Preisendörfer, Green and Greenback. The Behavioral Effects of Environmental Attitudes in Low-Cost and High-Cost Situations, Ration Soc 15(4) (2003) 441-472.

[38] S.Z. Attari, M.L. DeKay, C.I. Davidson, W. Bruine de Bruin, Public perceptions of energy consumption and savings, Proceedings of the National Academy of Sciences 107(37) (2010) 16054.

[39] M. Chitnis, S. Sorrell, A. Druckman, S.K. Firth, T. Jackson, Who rebounds most? Estimating direct and indirect rebound effects for different UK socioeconomic groups, Ecol Econ 106(0) (2014) 12-32.

[40] A.C. Merritt, D.A. Effron, B. Monin, Moral Self-Licensing: When Being Good Frees Us to Be Bad, Social and Personality Psychology Compass 4/5 (2010) 344-357.

[41] P. Mohai, D. Pellow, J.T. Roberts, Environmental Justice, Annual Reviewof Environmental Resources 34(405-430) (2009).

[42] W.M. Bowen, An Analytical Review of Environmental Justice Research: What Do We Really Know?, Environmental Management 29 (2002) 3-15.

[43] A. Diekmann, R. Meyer, Schweizer Umweltsurvey 2007. Dokumentation und Codebuch [Swiss Environmental Survey 2007. Documentation and Codebook], Chair of Sociology, ETH Zurich, Zurich, 2008.

[44] S. Van Buuren, Flexible Imputation of Missing Data, Chapman \& Hall / CRC, Boca Raton, 2012.

[45] I.R. White, P. Royston, A.M. Wood, Multiple imputation using chained equations: Issues and guidance for practice, Statistics in Medicine 30(4) (2011) 377-399. 
[46] StataCorp., Stata Multiple-Imputation Reference Manual. Release 12, Stata Press, College Station, Texas, 2011.

[47] D.A. Notter, R. Meyer, H.-J. Althaus, The Western Lifestyle and Its Long Way to Sustainability, Environ Sci Technol 47(9) (2013) 4014-4021.

[48] A. Diekmann, P. Preisendörfer, Umweltsoziologie. Eine Einführung [Environmental Sociology. An Introduction], Rowohlt, Reinbek bei Hamburg, 2001.

[49] M. Fairbrother, Rich People, Poor People, and Environmental Concern: Evidence across Nations and Time, European Sociological Review 29(5) (2013) 910-922.

[50] J.B. Hirsh, Personality and environmental concern, J Environ Psychol 30(2) (2010) 245-248.

[51] A. Franzen, D. Vogl, Two decades of measuring environmental attitudes: A comparative analysis of 33 countries, Global Environmental Change 23(5) (2013) 1001-1008.

[52] M. Büchs, N. Bardsley, S.V. Schnepf, Unequal emissions - unequal policy impacts: how do different areas of $\mathrm{CO} 2$ emissions compare?, in: T. Fitzpatrick (Ed.), International Handbook on Social Policy and the Environment, Edward Elgar, Cheltenham, 2014, pp. 62-92.

[53] E.H. Kennedy, H. Krahn, N.T. Krogman, Egregious Emitters: Disproportionality in Household Carbon Footprints, Environ Behav 46(5) (2014) 535-555.

[54] B. Girod, P. de Haan, GHG reduction potential of changes in consumption patterns and higher quality levels: Evidence from Swiss household consumption survey, Energy Policy 37(12) (2010) 5650-5661.

[55] Swiss Federal Statistical Office SFS, Tenants / owners, 2018.

https://www.bfs.admin.ch/bfs/en/home/statistics/construction-housing/dwellings/housing-

conditions/tenants-owners.html. (Accessed 2018.10.17.

[56] J. Frick, F. Kaiser, M. Wilson, Environmental knowledge and conservation behavior: exploring prevalence and structure in a representative sample, Pers Indiv Differ 37(8) (2004) 1597-1613.

[57] U. Liebe, J. Gewinner, A. Diekmann, What is missing in research on non-monetary incentives in the household energy sector?, Energy Policy 123 (2018) 180-183.

[58] A. Druckman, I. Buck, B. Hayward, T. Jackson, Time, gender and carbon: A study of the carbon implications of British adults' use of time, Ecol Econ 84(0) (2012) 153-163.

[59] A. Di Giulio, Ressourcenverbrauch als Bedürfnis? Annäherung an die Bestimmung von Lebensqualität im Kontext einer nachhaltigen Entwicklung [Is the consumption of natural resources a human want?], Wissenschaft \& Umwelt interdisziplinär 11 (2008) 228-237.

[60] M. Büchs, N. Bardsley, S. Duwe, Who bears the brunt? Distributional effects of climate change mitigation policies, Critical Social Policy 31(2) (2011) 285-307. 